CrossMark <click for updates

Cite this: Phys. Chem. Chem. Phys., 2015, 17, 14961

Received 11th February 2015 Accepted 6th May 2015

DOI: $10.1039 / c 5 c p 00876 j$

www.rsc.org/pccp

\section{Influence of fluoro and cyano substituents in the aromatic and antiaromatic characteristics of cyclooctatetraene $\dagger+$}

\author{
Goar Sánchez-Sanz, ${ }^{\star a}$ Cristina Trujillo, ${ }^{b}$ Isabel Rozas ${ }^{\mathrm{b}}$ and Ibon Alkorta ${ }^{\mathrm{c}}$
}

An exhaustive and systematic study of the structural and electronic properties of cyclooctatetraene (COT) upon substitution of hydrogen atoms by fluoro and cyano groups has been carried out in order to analyse the influence of both substituents on the aromaticity. We found that $\mathrm{C}-\mathrm{C}$ distances decrease with fluoro substitution while in cyano derivatives the opposite happens. All the compounds retain their original structural type, with the exception of the cyano derivatives; thus, compounds $25 \mathrm{CN}_{6 \mathrm{~T}}, \mathbf{2 7 C N}_{6 \mathrm{~T}}$ and $\mathbf{3 0 C N _ { 8 T }}$ show boat-like structure, whereas compounds $20 \mathrm{CN}_{5 \mathrm{~T}}, \mathbf{2 6} \mathrm{CN}_{6 \mathrm{~T}}$, and $\mathbf{2 9} \mathrm{CN}_{7 \mathrm{~T}}$ present twisted structures. Regarding the relative energies of those compounds with the same number of substitutions, it was found that compounds where the $\mathrm{X}$ groups were more separated among them were the most stable ones. Inversion barriers $\left(\Delta E_{\mathrm{TS}}\right)$ were found to increase with the number of substitutions; in the case of fluoro derivatives these barriers have a two-fold, increase compared to the parent compound while in the cyano ones a three-fold increase was observed. The aromatic character based on the NICS values, was found to increase in the ground singlet states and in the transition states of both fluoro and cyano derivatives. For triplet states, a decrease of the aromatic behaviour was found upon substitution. NICS profiles and 3D NICS isosurfaces confirm such findings. Finally, HOMA indexes corroborate the aromatic changes described by the NICS values, although, no good correlations between both quantities were found.

\section{Introduction}

The interest in the design and synthesis of cyclic $\pi$-conjugated systems, including aromatic and antiaromatic rings, has grown in the last years. ${ }^{1-4}$ Amongst all the possible aromatic, non aromatic and antiaromatic systems, cyclooctatetraene (COT) which is non-aromatic, and its inversion transition and triplet states (antiaromatic and aromatic, respectively), the first prepared $[4 n]$ annulene, has been the object of numerous investigations during several decades, ${ }^{5-13}$ in special in the field of organometallic chemistry for its capacity to bond to transition metals, lanthanides and actinides. ${ }^{14-16}$ In fact, COT, being a $4 n$ cyclic $\pi$-conjugated system, it is often considered as an example of a non-aromatic (or antiaromatic, when planar) species. ${ }^{17}$ COT

\footnotetext{
${ }^{a}$ School of Physics \& Complex and Adaptive Systems Laboratory, University College Dublin, Belfield, Dublin 4, Ireland. E-mail: goar.sanchez@ucd.ie

${ }^{b}$ School of Chemistry, Trinity Biomedical Sciences Institute, Trinity College Dublin, 152-160 Pearse St., Dublin 2, Ireland

'Instituto de Química Médica, CSIC, Juan de la Cierva, 3, E-28006 Madrid, Spain

$\dagger$ Dedicated to Prof. José Elguero on the occasion of his 80th anniversary.

\$ Electronic supplementary information (ESI) available: Supplementary data containing $\mathrm{C}-\mathrm{C}$ distances, Wiberg bond indexes, bond NICS values, HOMA indexes and NICS profiles calculated at the B3LYP/6-311++G(d,p) level of theory of all studied compounds. See DOI: 10.1039/c5cp00876j
}

ground state presents a strongly non-planar tub-shaped structure which has been established as a non-aromatic system. ${ }^{18}$ However, both the transition state (corresponding to the inversion of the boat-like structure) and the triplet state of COT show planar structures. The aromaticity of its planar triplet and transition state as well as the aromaticity/antiaromaticity inversion observed between the ground and the excited states of COT have been previously studied. ${ }^{18-21}$ Additionally, the properties of COT's hetero-derivatives as well as those of its dianion have also been explored in the literature. ${ }^{11,22-25}$ Besides, the reactivity of metallic derivatives of COT with carbon monoxide has been additionally explored at theoretical level. ${ }^{26}$

In the present study, we have focused in the effect that the systematic substitution of a hydrogen atom by a fluorine atom or a cyano group will have in the aromaticity/antiaromaticity of COT. We are aiming to answer two questions: (1) what is the effect of those substitutions on the ring structure? And (2) what is influence of those substitutions on the aromatic/antiaromatic characteristics of the singlet, triplet and transition states of the flouro and cyano derivatives of COT?

In Fig. 1, we show the structures of the compounds studied in the present work, including the systematic substitutions and nomenclature used along the article. In the present manuscript, compounds will be named as $\boldsymbol{n} \mathbf{X}_{i \mathbf{Y}}$, where $\boldsymbol{n}$ corresponds 


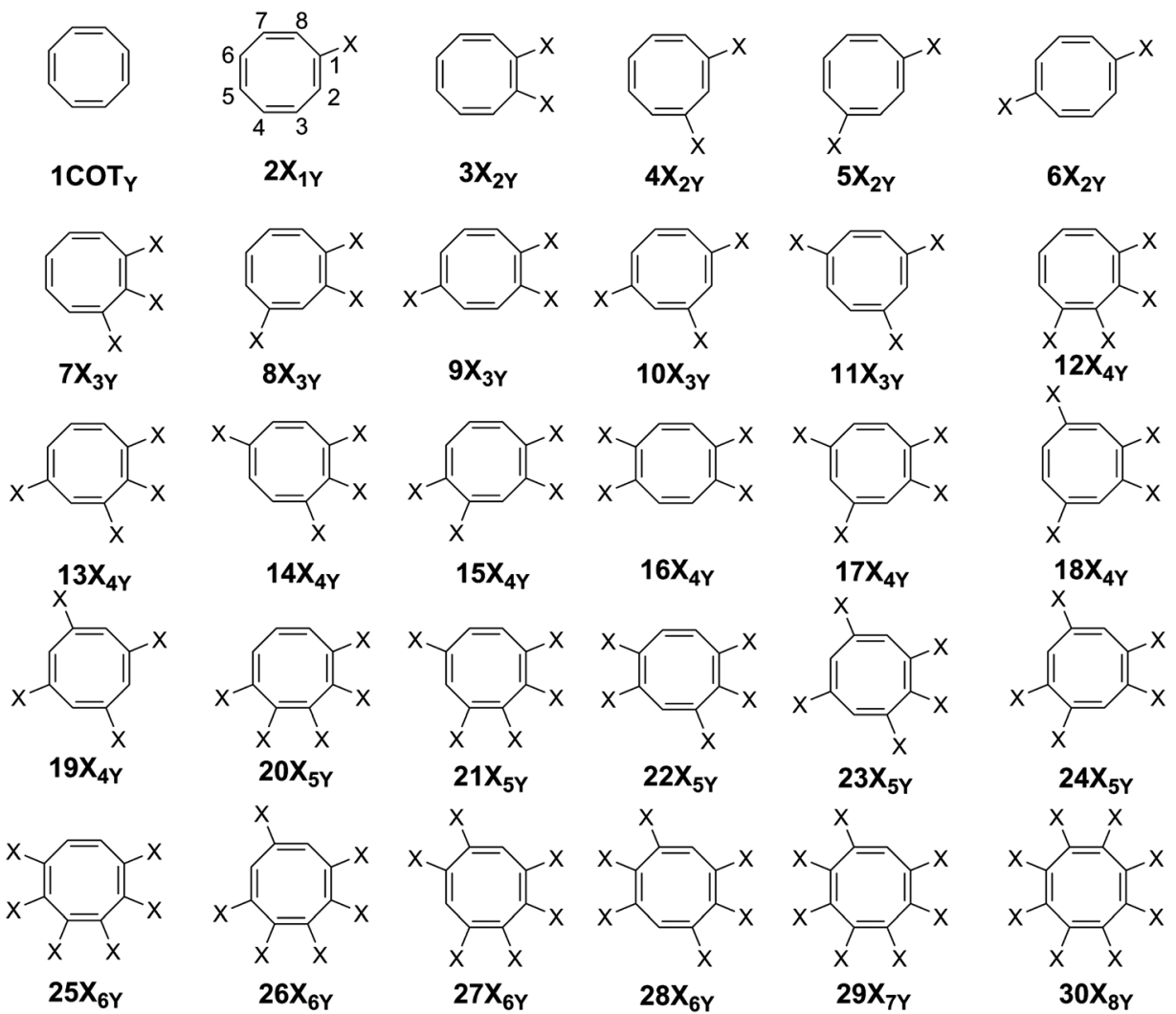

Fig. 1 Compounds studied in the present work.

to an ordinal compound number, $\mathbf{X}$ is the atom or group substituting $\mathrm{H}$ ( $\mathrm{F}$ or $\mathrm{CN}$ ), $\boldsymbol{i}$ denote the number of substitutions made with respect to the parent compound (i.e. СОT) and $\mathbf{Y}$ represents the state of the compound considered (S: singlet ground state, T: triplet and TS: singlet transition state). Some of these compounds, including $\mathbf{1 C O T}_{\mathbf{S}}$, have been synthesized and described in the literature: $2 \mathbf{F}_{\mathbf{1 S}}{ }^{27} \mathbf{2 5 F}_{\mathbf{6 S}},{ }^{28} \mathbf{3 0 F}_{\mathbf{8 S}}{ }^{29,30} \mathbf{2 C N}_{\mathbf{1 S}},{ }^{31,32}$ $\mathbf{3 C N}_{\mathbf{2 S}}{ }^{33}$ and $\mathbf{5 C N}_{2 \mathbf{S}} \cdot{ }^{34,35}$ Moreover, an accurate structure of $\mathbf{1 C O T}_{\mathbf{S}}$ has been obtained by combining femtosecond time-resolved rotational coherence spectroscopy and high-level $a b$ initio calculations. ${ }^{36}$ Finally, X-ray structures of $\mathbf{1 C O T}_{\mathbf{S}}$ and $\mathbf{3 0 F}_{\mathbf{8 S}}$ have been reported showing a boat shape. ${ }^{6,37,38}$

\section{Computational details}

The geometry of the systems has been optimized at the $\mathrm{B}^{2} \mathrm{LYP}^{39,40}$ / $6-311++G(d, p)^{41}$ computational level. Open shell systems have been obtained using the unrestricted UB3LYP functional. Harmonic vibrational frequencies were computed at the same computational level used for geometry optimizations in order to identify the stationary points either as local minima or transition states (TS).

NICS values ${ }^{42}$ were calculated using the GIAO method ${ }^{43,44}$ on the B3LYP/6-311++G(d,p) geometries. To obtain the spatial distribution of the NICS, these values have been calculated on a 3D cubic grid of $14 \AA$ size following the procedure described in our previous work..$^{20,45,46}$ The points in the grid are located at $0.2 \AA$ one from another in the three spatial directions. The result is a cube of 357911 NICS values, which in the next step are represented over the 0.001 a.u. electron density isosurface using the WFA program. ${ }^{47}$ All the calculations have been carried out using the Gaussian09 computational package. ${ }^{48}$

The natural bond orbital (NBO) method ${ }^{49}$ has been employed to evaluate the Wiberg bond indexes (WBI) within the natural resonance theory (NRT). ${ }^{50,51}$ In order to evaluate the $\pi$-electron delocalization on the compounds studied, and thus, their aromaticity, the harmonic oscillator model of aromaticity (HOMA) has been used. ${ }^{52,53}$

\section{Results}

We have studied the structural, energetic and aromatic changes in the COT derivatives upon substitution of $\mathrm{H}$ by $\mathrm{F}$ and $\mathrm{CN}$ groups.

\subsection{Structure}

The $\mathrm{C}-\mathrm{C}$ distances of those atoms belonging to the ring have been gathered in Table S1 (ESI ). However, for the sake of simplicity, average values of those $\mathrm{C}-\mathrm{C}$ distances have been included in Table 1 . The average values of the $\mathrm{C}-\mathrm{C}$ bonds distances, in addition to the standard deviation, provide with a view about the amount of variation in those specific bonds. Two different conformations have been found in COT derivatives, as it was already observed in the literature, ${ }^{18,20}$ boat-like and planar. As a general rule, the singlet states of the compounds studied present boat-like structures, while planar ones 
Table 1 Average C-C distances (Å) and average Wiberg bond indexes (WBI) for all the compounds optimized at B3LYP/6-311++G(d,p) computational level

\begin{tabular}{|c|c|c|c|c|c|c|c|c|c|c|c|c|c|c|c|}
\hline & $\frac{\mathrm{COT}(\mathrm{S})}{\text { Dist. }}$ & $\frac{\operatorname{COT}(\mathrm{T})}{\text { Dist. }}$ & $\frac{\mathrm{COT}(\mathrm{TS})}{\text { Dist. }}$ & \multicolumn{2}{|l|}{$\mathrm{F}(\mathrm{S})$} & \multicolumn{2}{|l|}{$\mathrm{F}(\mathrm{T})$} & \multicolumn{2}{|l|}{$\mathrm{F}(\mathrm{TS})$} & \multicolumn{2}{|l|}{$\mathrm{CN}(\mathrm{S})$} & \multicolumn{2}{|c|}{$\mathrm{CN}(\mathrm{T})$} & \multicolumn{2}{|c|}{$\mathrm{CN}$ (TS) } \\
\hline Total & 1.406 & 1.404 & 1.409 & $1.399^{a}$ & $1.41^{b}$ & 1.398 & 1.33 & $1.403^{a}$ & $1.40^{b}$ & $1.414^{a}$ & $1.39^{b}$ & 1.412 & 1.31 & $1.417^{a}$ & $1.37^{b}$ \\
\hline $\mathrm{C} 2-\mathrm{C} 3$ & 1.340 & 1.404 & 1.474 & 1.334 & 1.75 & 1.398 & 1.32 & 1.468 & 1.06 & 1.348 & 1.72 & 1.416 & 1.30 & 1.485 & 1.05 \\
\hline $\mathrm{C} 3-\mathrm{C} 4$ & 1.472 & 1.404 & 1.343 & 1.461 & 1.06 & 1.398 & 1.33 & 1.339 & 1.74 & 1.481 & 1.03 & 1.416 & 1.30 & 1.357 & 1.69 \\
\hline C4-C5 & 1.340 & 1.404 & 1.474 & 1.335 & 1.77 & 1.397 & 1.33 & 1.468 & 1.06 & 1.347 & 1.74 & 1.413 & 1.30 & 1.480 & 1.05 \\
\hline $\mathrm{C} 8-\mathrm{C} 1$ & 1.340 & 1.404 & 1.474 & 1.333 & 1.77 & 1.394 & 1.34 & 1.464 & 1.07 & 1.347 & 1.74 & 1.412 & 1.31 & 1.480 & 1.05 \\
\hline
\end{tabular}

are characteristic of triplet and transition states. However, in triplet states, while all fluoro derivatives remain planar upon substitution, cyano derivatives present different conformations. Compounds $\mathbf{2 C N}_{\mathbf{1 T}}$ to $\mathbf{1 9 C N}_{4 \mathrm{~T}}, \mathbf{2 1 C N}_{\mathbf{5 Y}}$ to $\mathbf{2 4 C N}_{5 \mathrm{~T}}$ and $28 \mathbf{C N}_{\mathbf{6 T}}$ remain planar, while $\mathbf{2 5 C N}_{\mathbf{6 T}}, \mathbf{2 7}_{\mathbf{C N}}$, and $\mathbf{3 0} \mathbf{C N}_{\mathbf{8 T}}$ show boat-like conformation and derivatives $\mathbf{2 0 C N}_{\mathbf{5 T}}, \mathbf{2 6 C N}_{\mathbf{6 T}}$, and $\mathbf{2 9} \mathbf{C N}_{\mathbf{7 T}}$ present twist structures as a consequence of the substitution.

Regarding the $\mathrm{C}-\mathrm{C}$ distances, as observed in Table 1, compounds with singlet state, both ground and transition states, show alternant single and double bond, while the triplet states present distances which resemble to those in benzene. Indeed, Wiberg bond indexes corroborate such findings, being close to 1 those with larger bond distances (single bonds), 1.7-1.8 for those with shorter ones (double bonds), and around 1.3 in those benzene-like (Benzene WBI $=1.4$ ).

When the nature of substituents is taken into account, the $\mathrm{C}-\mathrm{C}$ bond distances in the fluoro derivatives have been found to be shorter than those in cyano derivatives in all the cases (i.e. singlet, triplet and transition states). For example, if we consider the average of the same $\mathrm{C}-\mathrm{C}$ bond for all the compounds (i.e. $\mathrm{C} 1-\mathrm{C} 2$ ), standard deviations of all the $\mathrm{C}_{x}-\mathrm{C}_{y}$ bonds for both $\mathrm{F}$ and $\mathrm{CN}$ derivatives remain between 0.002-0.009 for fluoro derivatives, while the cyano ones present a wider range of values $0.003-0.018$.

Looking at that data, two different structures have been found, alternated-bond (S and TS) and benzene-like (T) structures. This is also corroborated by the standard deviations of the values on the average of all the $\mathrm{C}-\mathrm{C}$ bonds, which present large standard deviations (0.063-0.067) in the alternated-bond structures similar to the one found in unsubstituted COT (0.066), while in benzene-like ones these standard deviations remain in the range of $0.006-0.014$, for $\mathrm{F}$ and $\mathrm{CN}$ containing systems, respectively. However, it is worth noting that the range for the cyano derivatives is twice that of the fluoro ones.

To study the evolution of the $\mathrm{C}-\mathrm{C}$ distance changes within the ring upon substitution, we have carried out two different analyses. First, we have studied the evolution of the $\mathrm{C}-\mathrm{C}$ average distances (averaging over the single and double bonds separately), upon substitution in two or more contiguous positions until the full substitution of all $\mathrm{H}$ in the ring by $\mathrm{X}$ has taken place (Seq, Fig. 2). Additionally, we have analysed the

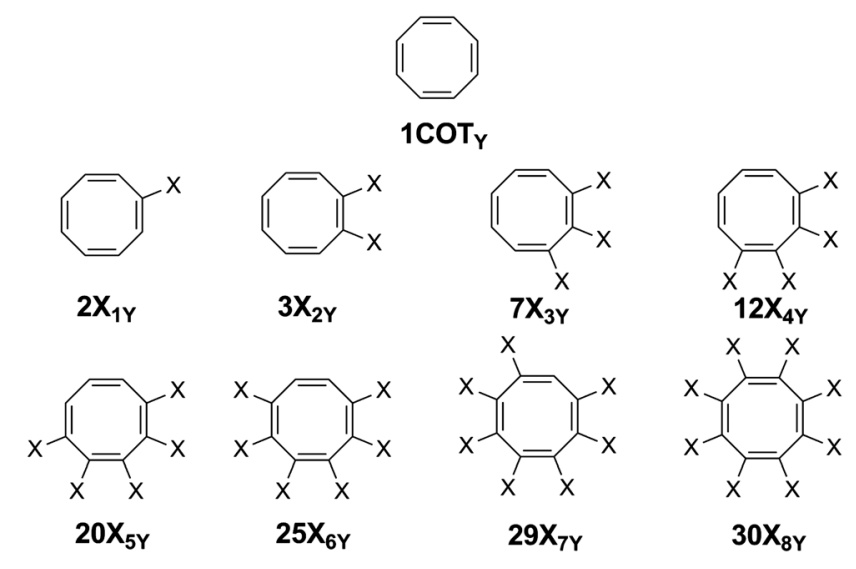

Fig. 2 Sequential substitutions of $\mathrm{H}$ atoms in the COT ring by $\mathrm{X}$ groups.

effect of the substitution using the average (Avg) $\mathrm{C}-\mathrm{C}$ values (averaging over all $\mathrm{C}-\mathrm{C}$ in molecules with the same number of substitutions), taking into account the nature of the bond (single, double and benzene-like).

Fig. 3 and Fig. S1 (ESI $\$$ ) show the evolution of the $\mathrm{C}-\mathrm{C}$ distance with the number of substitutions. Single bonds in the $\mathrm{F}$ derivatives suffer a slight decrease in the $\mathrm{C}-\mathrm{C}$ distance, from 1.472 (1COT) up to $1.457 \AA\left(\mathbf{3 0 F}_{\mathbf{8 s}}\right)$, while the opposite happens for the $\mathrm{CN}$ ones, up to $1.493 \AA\left(\mathbf{3 0 C N}_{\mathbf{8 s}}\right)$ both in the sequential (Seq) and average (Avg) data sets. Double bonds present similar trends, increasing $\mathrm{C}-\mathrm{C}$ bond length with $\mathrm{X}=\mathrm{CN}$ substitutions, while in for $\mathrm{X}=\mathrm{F}$ the curve have a symmetrical well-like profile, with a minimum at $i=4$. This behaviour was also observed for $\mathrm{C}-\mathrm{C}$ bonds when considering triplet and transition states (Fig. S1, ESI $\$$ ). It appears that in $\mathrm{X}=\mathrm{F}$ derivatives, the effect of the saturation by the $\mathrm{F}$ atoms reaches a maximum with four substituents and, accordingly, the reduction on the $\mathrm{C}-\mathrm{C}$ distance caused by them also reaches a limit. Further substitutions do not reduce the $\mathrm{C}-\mathrm{C}$ distances anymore, but slightly increase them.

In order to get an insight into the non-planarity of the boatlike systems (singlet ground state), for both $\mathrm{F}$ and $\mathrm{CN}$ derivatives, we have measured the distance between the centre of the four top $\mathrm{C}$ atoms, and the centre of the four $\mathrm{C}$ atoms at the bottom, in other words, the module of the molecular middle 

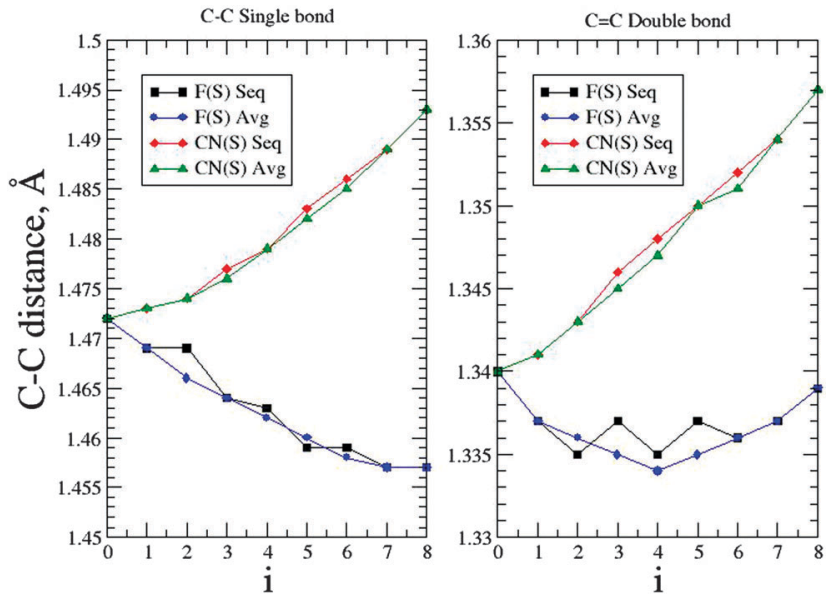

Fig. 3 Evolution of the $\mathrm{C}-\mathrm{C}$ distance upon substitution of the ring, for singlet state in $\mathrm{F}$ and $\mathrm{CN}$ compounds vs. the number of substituents in each molecule, i. Sequential substitution (Seq) and average over the distances with the same i (Avg) are shown.

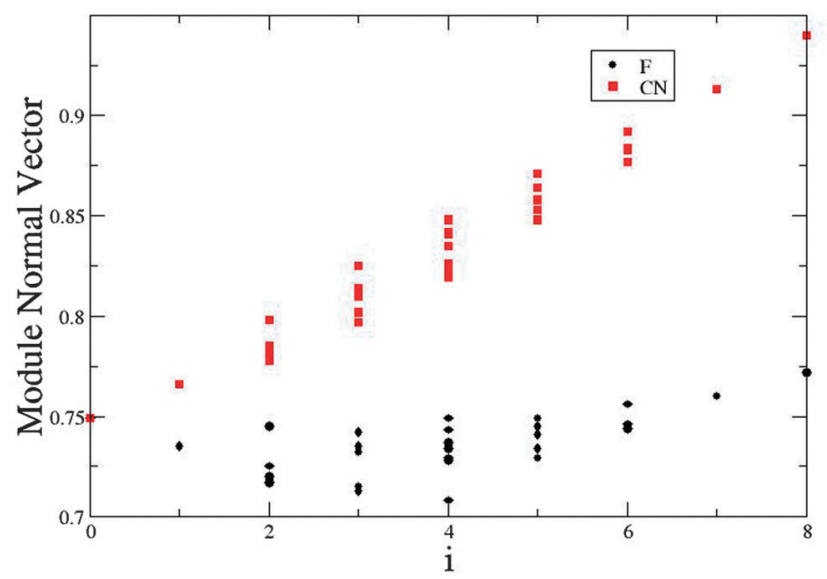

Fig. 4 Module of the molecular middle plane normal vector, in $\AA$, versus the number of substitutions, i. Red squares and black dots correspond to fluoro and cyano derivatives respectively.

plane normal vector. We observed that the larger the module, the lesser the planarity, therefore indicating a decrease in the electron delocalisation. As presented in Fig. 4, increasing the number of substitutions results in a decrease of the planarity of the boat-like structures in the cyano derivatives, since the module of the normal vector increases more or less linearly with the substitutions. In fluoro derivatives, the module of the vector remains between $0.70-0.77$ along the series, showing less influence in the electron delocalisation, and therefore less ring puckering, than in the cyano derivatives.

\subsection{Energy}

The relative energies with respect to the most stable system with the same number of substitutions have been gathered in Table 2. In all families of compounds with the same number of substitutions, the most stable ones are those where the substitutions are alternated keeping the longest distance between the substituted $\mathrm{C}$ atoms. In other words, those compounds with sequential substitutions seem to have higher relative energies (least stable) than the rest. Similar results have been reported for the aza-substitution in platonic hydrocarbon systems. ${ }^{54-56}$

However, despite the most stable structure corresponding to that with highest alternated substitution, in almost all the cases, for both substituents isomers are found to be close in energy to the most stable one. For example, three isomers with two substitutions are found within a range of 0.3-4.9 and 0.8$4.2 \mathrm{~kJ} \mathrm{~mol}^{-1}$ for $\mathrm{F}$ and $\mathrm{CN}$ derivatives, respectively. Similar features are found in the rest of the families, except in the case of fluoro derivatives with four contiguous $\mathrm{F}$ atoms. Thus, compounds $19 \mathbf{F}_{\mathbf{4 Y}}(\mathrm{Y}=\mathrm{S}, \mathrm{T}$ and $\mathrm{TS})$ are the most stable being the next isomers at 22.0, 10.1 and $34.3 \mathrm{~kJ} \mathrm{~mol}^{-1}$ for singlet, triplet and transition states, respectively. For these cases, the optimal structure of $\mathbf{1 9 F}_{\mathbf{4 Y}}$ is that with the highest possible separation between the substitutions. However, compounds $\mathbf{1 9 C N}_{\mathbf{4 Y}}$ do not present the same tendency, since $\mathbf{1 9 C N}_{\mathbf{4 S}}$ and $\mathbf{1 9 C N}_{\mathbf{4 T}}$ have isomers within a range of 3.4-3.6 and 7.6-7.7 $\mathrm{kJ} \mathrm{mol}^{-1}$ respectively. This is a clear indication of the structural effect of the different substituents.

A Free-Wilson model ${ }^{57,58}$ has been proposed to analyse the substituent interactions in a general manner. Thus, four parameters $(D 1-D 4)$ have been proposed based on the $\mathrm{C}-\mathrm{C}$ bonds that separate each pair of substituents in the shortest way. For example, $\mathbf{7} \mathbf{X}_{\mathbf{3 Y}}$ will be defined by the $D 1-D 4$ parameters $1,1,0,0$ while $\mathbf{8} \mathbf{X}_{\mathbf{3 Y}}$ will be defined by $1,1,1,0$. In order to be able to compare the relative energies $\left(E_{\mathrm{rel}}\right)$, the parameters for each compound have been subtracted from those of the most stable isomer, as defined in eqn (1).

$$
E_{\text {rel }}=a_{1} D 1+a_{2} D 2+a_{3} D 3+a_{4} D 4
$$

The results are shown in Table 3. The program used for the fitting, fixes one of the variables to 0.0 for the matrix proposed, in this case $a_{3}$. The good correlation coefficient obtained for all the cases indicate that this simple model is able to reproduce with high accuracy the results obtained. The values of the fitted parameters show that the larger penalty in the singlet derivatives of both series corresponds to the presence of contiguous substituents $\left(a_{1}\right)$ and when $\mathrm{X}=\mathrm{F}$, this penalty is twice larger $\left(13.1 \mathrm{~kJ} \mathrm{~mol}^{-1}\right)$ than when $\mathrm{X}=\mathrm{CN}\left(7.5 \mathrm{~kJ} \mathrm{~mol}^{-1}\right)$. In addition, the presence of substituents separated by two or four $\mathrm{C}-\mathrm{C}$ bonds $\left(a_{2}\right.$ and $a_{4}$ ) stabilized $-2.5 \mathrm{~kJ} \mathrm{~mol}^{-1}$ in the fluoro derivatives while in the cyano substituted systems, the separation by two $\mathrm{C}-\mathrm{C}$ bonds produces a destabilization of $1.7 \mathrm{~kJ} \mathrm{~mol}^{-1}$ and the four $\mathrm{C}-\mathrm{C}$ bond separation a stabilization of $-0.5 \mathrm{~kJ} \mathrm{~mol}^{-1}$ compared to compounds with two substituents separated by three $\mathrm{C}-\mathrm{C}$ bonds.

In the case of the compounds in triplet configuration, all the fitted parameters show positive values except for $a_{3}$, which is fixed to 0 in the regression. For these compounds the energy penalty of contiguous substitution $\left(a_{1}\right)$ is almost twice that of compounds in the singlet configuration (23.2 vs. $13.1 \mathrm{~kJ} \mathrm{~mol}^{-1}$ for the fluoro derivatives in triplet and singlet electronic configurations respectively, and 18.4 and $7.5 \mathrm{~kJ} \mathrm{~mol}^{-1}$ for the cyano ones). The $a_{2}$ parameter is around 4.0 for the two families and 
Table 2 Relative energies ( $\mathrm{kJ} \mathrm{mol}{ }^{-1}$ ) amongst compounds with same number of substitutions, energy differences between singlet and triplet states $\left(\Delta E_{\mathrm{S}-\mathrm{T}}, \mathrm{kJ} \mathrm{mol}{ }^{-1}\right)$ and transition energy barriers $\left(\Delta E_{\mathrm{TS}}, \mathrm{kJ} \mathrm{mol}^{-1}\right)$ for all the compounds studied at B3LYP/6-311++G(d,p)

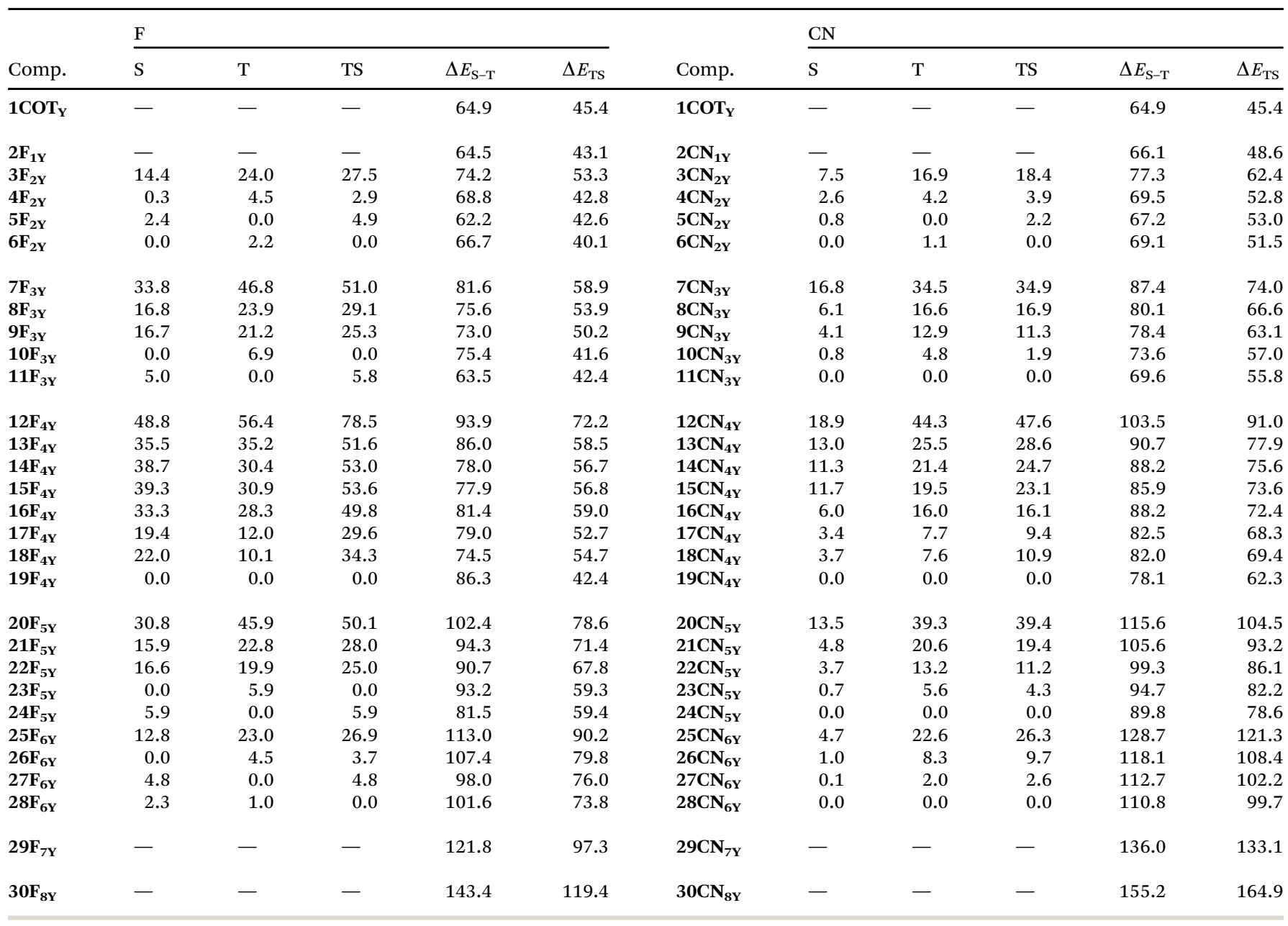

Table 3 Fitted parameters and square correlation coefficients in the Free-Wilson model shown in eqn (1)

\begin{tabular}{lllll}
\hline $\begin{array}{l}\text { Fitted } \\
\text { parameter }\end{array}$ & $\mathrm{F}(\mathrm{S})$ & $\mathrm{CN}(\mathrm{S})$ & $\mathrm{F}(\mathrm{T})$ & \multicolumn{1}{c}{$\mathrm{CN}(\mathrm{T})$} \\
\hline$a_{1}$ & $13.14 \pm 0.63$ & $7.46 \pm 0.48$ & $23.21 \pm 1.55$ & $18.42 \pm 1.66$ \\
$a_{2}$ & $-2.46 \pm 0.41$ & $1.70 \pm 0.30$ & $3.84 \pm 1.00$ & $4.20 \pm 1.07$ \\
$a_{3}$ & 0.00 & 0.00 & 0.00 & 0.00 \\
$a_{4}$ & $-2.47 \pm 0.55$ & $-0.46 \pm 0.41$ & $0.81 \pm 1.35$ & $0.13 \pm 1.44$ \\
$R^{2}$ & 0.99 & 0.97 & 0.97 & 0.94
\end{tabular}

finally, $a_{4}$ is small and with an error larger than the parameter itself which indicate that it is not statistically significant.

We have analysed the relative energies between singlet and triplet states, as well as the energy difference between the singlet ground states and the transition states, i.e. the inversion barrier (see Fig. 5). The inversion barrier of singlet boat-like structures increases with the number of substitutions, being more than twice in $\mathbf{3 0} \mathbf{X}_{\mathbf{8 S}}$ than in the parent compound 1COT, both for $\mathrm{F}$ and $\mathrm{CN}$ derivatives. However, fluoro derivatives show smaller inversion barriers than those with cyano substituents. Looking at the dependence of such barrier with those structures with the same number of substitutions (Table 2), it is

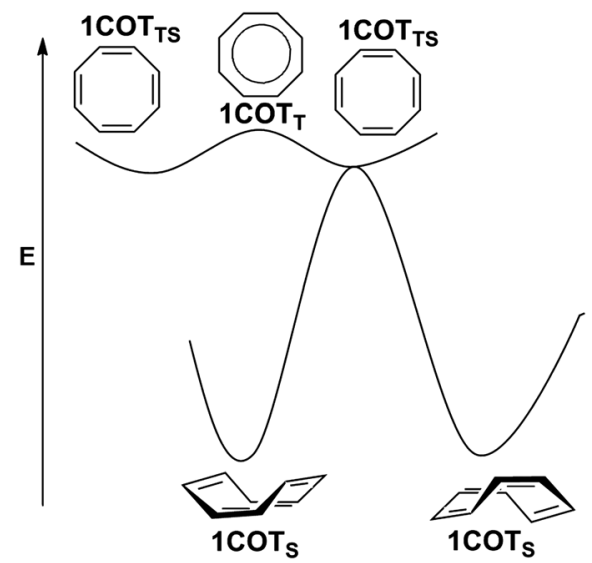

Fig. 5 Schematic view of the potential energy surface corresponding to the inversion barrier in ground state (S) systems and the relationship between triplet (T) and transition states (TS). Arrow indicates the energy axis.

clearly shown that, as happened with the relative energies, those structures with the highest possible alternated groups present the smallest inversion barriers, while those with contiguous $\mathrm{X}$ groups show the largest ones. 
Regarding the relative stability between singlet and triplet states, there is a significant increase with the number of substitutions, being this increment more pronounced in cyano derivatives than in fluoro ones.

\subsection{Aromaticity studies: NICS, NICS-profiles, 3D-NICS isosurfaces and HOMA indexes}

In order to study the aromaticity of all the compounds considered, we have calculated NICS values at 0, 1 and $2 \AA$ over the ring centre of each molecule. To avoid possible interactions with the magnetic field of the atoms, several authors ${ }^{53,59-64}$ recommend extending the calculations up to $2 \AA$. Some authors ${ }^{59,65-67}$ prefer the use of NICS(zz) [also called NICS(out-of-plane)] component to describe (anti)aromaticity. It is known that in some cases, NICS can diagnose delocalization and NICSzz predicts the opposite behavior or vice versa. It has been shown that this occurs mainly because NICS values are contaminated by the in-plane contributions. ${ }^{68,69}$ However, in our case, the isotropic values have proved to follow similar behaviour and tendencies than NICS(zz). ${ }^{70}$ Following our previous experience, the average NICS instead of the NICS(zz) component has been chosen. All calculated NICS values obtained at 0,1 , and $2 \AA$ have been gathered in Table 4 and Table S3 (ESI $\$$ ).

Singlet state compounds, both in fluoro and cyano derivatives, suffer a slight increase of the NICS values just with the first substitution, i.e. there is an increase in the electron delocalisation. Taking into account only fluoro derivatives, singlet state structures show a decrease in NICS 0,1 , and 2 from 3.9, 0.9 and $0.7 \mathrm{ppm}\left(\mathbf{2 F}_{\mathbf{1 s}}\right)$ to $-7.2,-5.1$, and $-1.5 \mathrm{ppm}$ $\left(\mathbf{3 0 F}_{\mathbf{8 s}}\right)$, respectively, indicating a loss of antiaromaticity. In the case of singlet state cyano derivatives, similar tendencies have been observed, with slightly less variations in the NICS values upon substitution.

Triplet state fluoro derivatives exhibit a drop in the NICS 0 and 1 values, across the series, showing an increase of aromatic character (more negative NICS values), with the exception of NICS 2 which slightly increases. However, the opposite is observed for triplet state cyano derivatives, which present a partial loss of aromaticity. This lost is indicated by an increase of the NICS 0,1 , and 2 values from $-10.7,-10.5$, and $-6.1 \mathrm{ppm}$ $\left(\mathbf{2 C N}_{\mathbf{1 T}}\right)$ to $-7.2,-7.7$, and $-4.3 \mathrm{ppm}\left(\mathbf{3 0 C N}_{\mathbf{8 T}}\right)$, respectively. The reason behind this different behaviour between $\mathrm{F}$ and $\mathrm{CN}$ substituents lays on the electron withdrawing and retrodonation capacities of both substituents and it will be discussed at the end of this section.

Finally, regarding transition states, fluoro derivatives show a strong anti-aromatic behaviour clearly noted by the large positive NICS 0, 1 and 2 values. Upon substitution, these values suffer a pronounced decrease (up to $16 \mathrm{ppm}$ ) indicating a loss of antiaromaticity in $\boldsymbol{n F}_{\boldsymbol{i T s}}$ compounds. In the case of cyano derivatives, a similar evolution on the NICS values has been found, suggesting a loss in the antiaromatic character with the

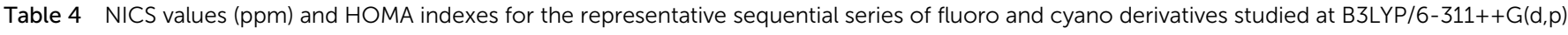
computational level

\begin{tabular}{|c|c|c|c|c|c|c|c|c|c|}
\hline \multirow[b]{2}{*}{ Compound } & \multicolumn{3}{|l|}{ NICS } & \multirow[b]{2}{*}{ HOMA } & \multirow[b]{2}{*}{ Compound } & \multicolumn{3}{|l|}{ NICS } & \multirow[b]{2}{*}{ HOMA } \\
\hline & 0 & 1 & 2 & & & 0 & 1 & 2 & \\
\hline $\mathbf{1 C O T}_{\mathrm{S}}$ & 4.9 & 1.0 & 0.7 & -0.21 & & & & & \\
\hline $2 F_{1 S}$ & 3.9 & $0.9^{a}$ & $0.7^{a}$ & -0.17 & $2 \mathrm{CN}_{1 \mathrm{~S}}$ & 3.9 & $0.5^{c}$ & $0.4^{c}$ & -0.22 \\
\hline $3 F_{2 S}$ & 1.8 & -0.5 & 0.1 & -0.20 & $3 \mathbf{C N}_{2 \mathrm{~S}}$ & 2.5 & -0.8 & -0.1 & -0.25 \\
\hline $7 \mathbf{F}_{3 S}$ & 0.1 & -1.8 & -0.4 & -0.08 & $7 \mathrm{CN}_{3 \mathrm{~S}}$ & 1.5 & -1.8 & -0.5 & -0.28 \\
\hline $12 F_{4 S}$ & -1.8 & -2.7 & -0.7 & -0.09 & $12 \mathrm{CN}_{4 \mathrm{~S}}$ & 0.7 & -2.4 & -0.7 & -0.32 \\
\hline $20 F_{5 S}$ & -3.4 & $-3.3^{b}$ & $-0.9^{b}$ & 0.01 & $20 \mathrm{CN}_{5 \mathrm{~S}}$ & -0.1 & $-2.8^{d}$ & $-0.9^{d}$ & -0.37 \\
\hline $25 F_{6 S}$ & -4.6 & -3.9 & -1.1 & -0.01 & $25 \mathrm{CN}_{6 \mathrm{~S}}$ & -1.2 & -3.6 & -1.3 & -0.43 \\
\hline $29 F_{7 S}$ & -5.8 & -4.6 & -1.4 & 0.06 & $29 \mathrm{CN}_{7 \mathrm{~S}}$ & -1.3 & -3.8 & -1.2 & -0.49 \\
\hline $30 F_{8 s}$ & -7.2 & -5.1 & -1.5 & 0.08 & $30 \mathrm{CN}_{8 \mathrm{~s}}$ & -2.9 & -4.7 & -1.8 & -0.56 \\
\hline $\mathbf{1 C O T}_{\mathrm{T}}$ & -11.1 & -11.0 & -6.4 & 0.94 & & & & & \\
\hline $2 \mathbf{F}_{1 \mathrm{~T}}$ & -11.3 & -10.8 & -6.1 & 0.96 & $2 \mathrm{CN}_{1 \mathrm{~T}}$ & -10.7 & -10.5 & -6.1 & 0.91 \\
\hline $3 F_{2 T}$ & -11.9 & -11.0 & -6.1 & 0.96 & $3 \mathbf{C N}_{2 \mathrm{~T}}$ & -10.2 & -10.1 & -5.8 & 0.87 \\
\hline $7 \mathbf{F}_{3 T}$ & -12.5 & -11.1 & -6.1 & 0.96 & $7 \mathbf{C N}_{3 \mathrm{~T}}$ & -10.4 & -10.1 & -5.9 & 0.82 \\
\hline $12 F_{4 T}$ & -13.1 & -11.4 & -6.1 & 0.96 & $12 \mathbf{C N}_{4 T}$ & -9.7 & -9.4 & -5.4 & 0.76 \\
\hline $20 F_{5 T}$ & -13.5 & -11.5 & -6.0 & 0.95 & $20 \mathrm{CN}_{5 \mathrm{~T}}$ & -9.5 & -9.2 & -5.5 & 0.72 \\
\hline $25 F_{6 T}$ & -14.3 & -11.7 & -6.1 & 0.95 & $25 \mathrm{CN}_{6 \mathrm{~T}}$ & -9.0 & -8.8 & -5.2 & 0.70 \\
\hline $29 F_{7 T}$ & -14.6 & -11.8 & -6.0 & 0.95 & $29 \mathrm{CN}_{7 \mathrm{~T}}$ & -8.0 & -8.1 & -4.6 & 0.64 \\
\hline $30 F_{8 T}$ & -15.1 & -12.0 & -5.9 & 0.94 & $30 \mathbf{C N}_{8 \mathrm{~T}}$ & -7.2 & -7.7 & -4.3 & 0.62 \\
\hline $\mathbf{1 C O T}_{\mathrm{TS}}$ & 41.0 & 32.5 & 16.3 & -0.22 & & & & & \\
\hline $2 F_{1 T S}$ & 38.0 & 30.1 & 15.0 & -0.17 & $2 \mathbf{C N}_{1 T S}$ & 39.6 & 31.3 & 15.6 & -0.21 \\
\hline $3 F_{2 T S}$ & 35.5 & 28.3 & 14.0 & -0.12 & $3 \mathbf{C N}_{2 \mathrm{TS}}$ & 38.9 & 30.8 & 15.3 & -0.22 \\
\hline $7 \mathbf{F}_{3 T S}$ & 33.3 & 26.7 & 13.2 & -0.17 & $7 \mathbf{C N}_{3 T S}$ & 37.4 & 29.6 & 14.6 & -0.24 \\
\hline $12 F_{4 T S}$ & 30.7 & 24.7 & 12.1 & -0.14 & $12 \mathrm{CN}_{4 \mathrm{TS}}$ & 35.2 & 27.8 & 13.7 & -0.28 \\
\hline $20 F_{5 T S}$ & 28.7 & 23.3 & 11.4 & -0.19 & $20 \mathrm{CN}_{5 \mathrm{TS}}$ & 32.5 & 25.7 & 12.5 & -0.32 \\
\hline $25 F_{6 T S}$ & 26.4 & 21.6 & 10.6 & -0.28 & $25 \mathrm{CN}_{6 \mathrm{TS}}$ & 31.6 & 24.9 & 12.2 & -0.34 \\
\hline $29 F_{7 T S}$ & 24.3 & 20.0 & 9.8 & -0.20 & $29 \mathrm{CN}_{7 \mathrm{TS}}$ & 28.4 & 22.5 & 10.8 & -0.33 \\
\hline $\mathbf{3 0 F}_{\mathbf{8 T S}}$ & 22.4 & 18.7 & 9.2 & -0.26 & $30 C N_{8 T S}$ & 27.6 & 21.8 & 10.7 & -0.40 \\
\hline
\end{tabular}




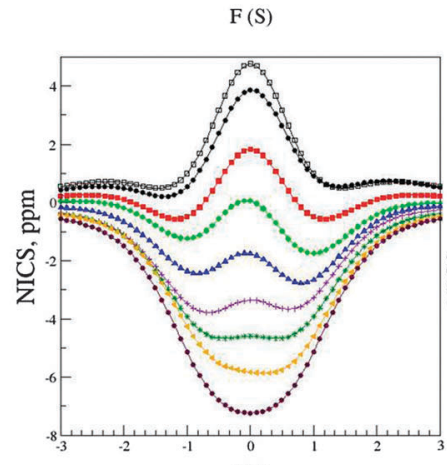

$\mathrm{F}(\mathrm{T})$
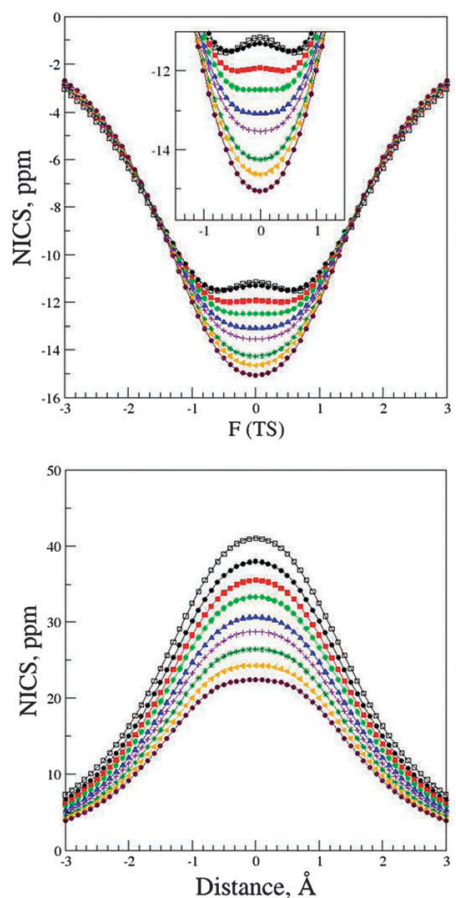

$\mathrm{CN}(\mathbf{S})$

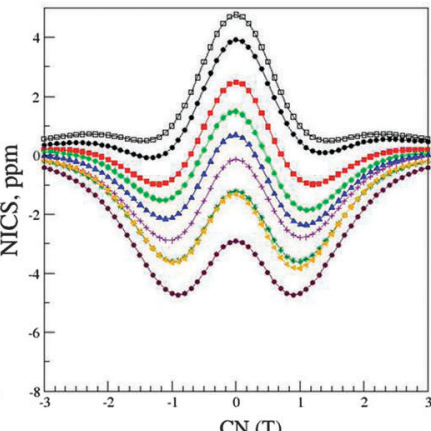

$$
\begin{aligned}
& \longrightarrow 1 \mathrm{COT}_{\mathrm{Y}} \\
& \longrightarrow 2 \mathrm{~F}_{1 \mathrm{Y}} \\
& \longleftrightarrow 3 \mathrm{~F}_{2 \mathrm{Y}} \\
& \longleftrightarrow 12 \mathrm{~F}_{3 \mathrm{Y}} \\
& \longleftrightarrow 20 \mathrm{~F}_{5 \mathrm{Y}} \\
& \longleftrightarrow 25 \mathrm{~F}_{6 \mathrm{Y}} \\
& \longleftrightarrow 29 \mathrm{~F}_{7 \mathrm{Y}} \\
& \longrightarrow 30 \mathrm{~F}_{8 \mathrm{Y}}
\end{aligned}
$$
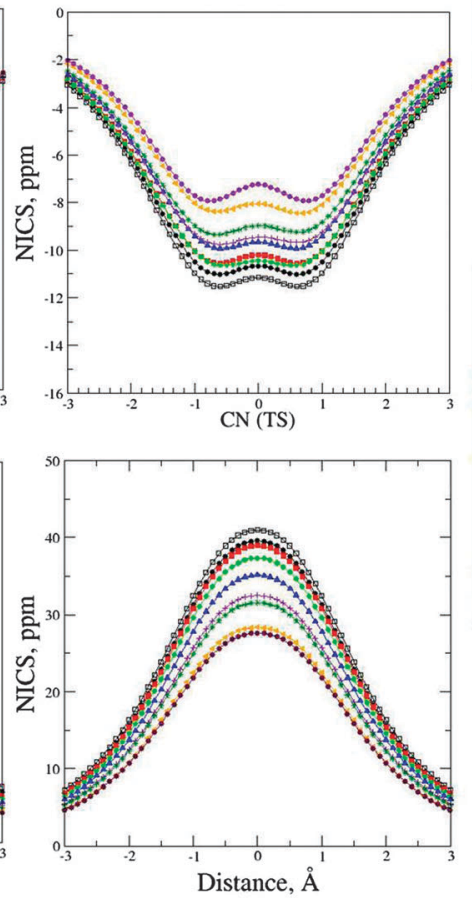

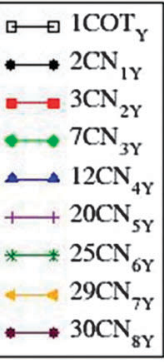

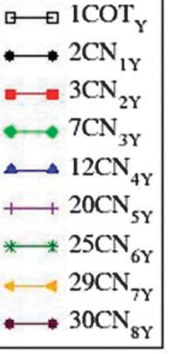

Fig. 6 NICS profiles along the axis through the centre of the ring of a sequential series of substitutions calculated at B3LYP/6-311++G(d,p) computational level. Top: singlet states; middle: triplet state; bottom: transition states. Left, fluoro and right, cyano derivatives respectively.

number of CN groups. Despite those drastic decreases of the NICS values with respect to the $\mathbf{C O T}_{\mathbf{T S}}$, transition states for both fluoro and cyano derivatives remain antiaromatic in all the cases.

In order to provide a deeper understanding of the evolution of the aromatic character of COT upon substitution, NICS values have been calculated along the axis perpendicular to the molecular plane, from 0 to $3 \AA$ with a step of $0.1 \AA$. These NICS profiles for a sequential substitution are plotted in Fig. 6 . Thus, Fig. 6 shows two different profiles for those fluoro and cyano derivatives with singlet state. While in the fluoro, substituted systems NICS 0 is a maximum in the curve of compound $\mathbf{2} \mathbf{F}_{\mathbf{1 s}}$, it is a minimum in that of $\mathbf{3 0 F}_{\mathbf{8 s}}$. Additionally, the systematic decrease on the NICS values of the curves upon substitution is observed. However, in cyano derivatives the changes in the curves are different. Upon substitution, the minimum of the curve corresponds to NICS 1 . The different behaviour in both substituents' series may be caused by their influence in the electron density of the ring. It is worth noting that due to the different environments in the non-planar structures (i.e. top and bottom), the curves obtained for singlet ground states are asymmetric. However, despite that asymmetry, values at both sides (with respect to NICS 0) are very similar among them, and no significant variation can be extracted between the positive values and its negative images, i.e. $\operatorname{NICS}(1)$ and NICS $(-1)$. Finally, evolution of the NICS values belonging to transition states reveals a Gaussian type curve in which the maximum is located at NICS 0 values. Despite the pronounced decrease of the height of the maximum, the shape is similar upon substitution and no substantial changes are noticeable.

In addition, the NICS values on the 0.001 a.u. electron density isosurface have been used to visualize the (anti)aromatic character of some of the compounds. In particular, the corresponding isosurfaces for compounds $\mathbf{1 C O T}_{\mathbf{Y}}, \mathbf{1 9 X}_{\mathbf{4 Y}}$ and $\mathbf{3 0 \mathbf { X } _ { \mathbf { 8 Y } }}$ are presented in Fig. 7. In singlet states, there is an increase of the aromatic character from $\mathbf{1 C O T}_{\mathbf{S}}$ to $\mathbf{3 0 \mathbf { X } _ { \mathbf { 8 S } }}$, i.e. a slight colour change in the central area over the ring from red (positive NICS 

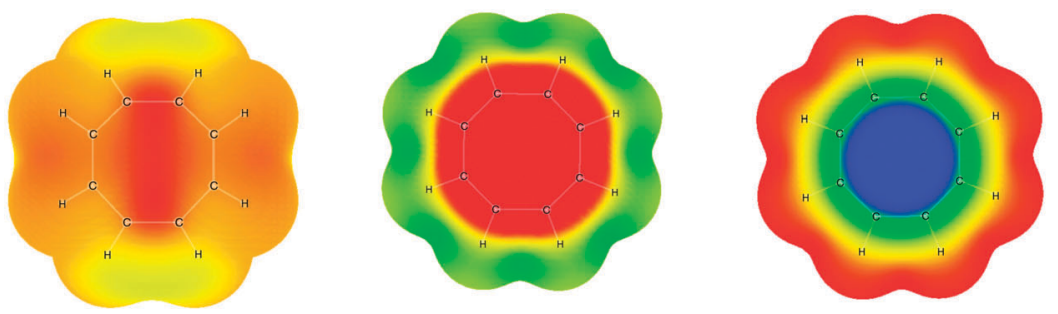

${ }_{1 C O T}$

$\mathrm{ICOT}_{\mathrm{TS}}$

$\mathrm{ICOT}_{\mathrm{T}}$
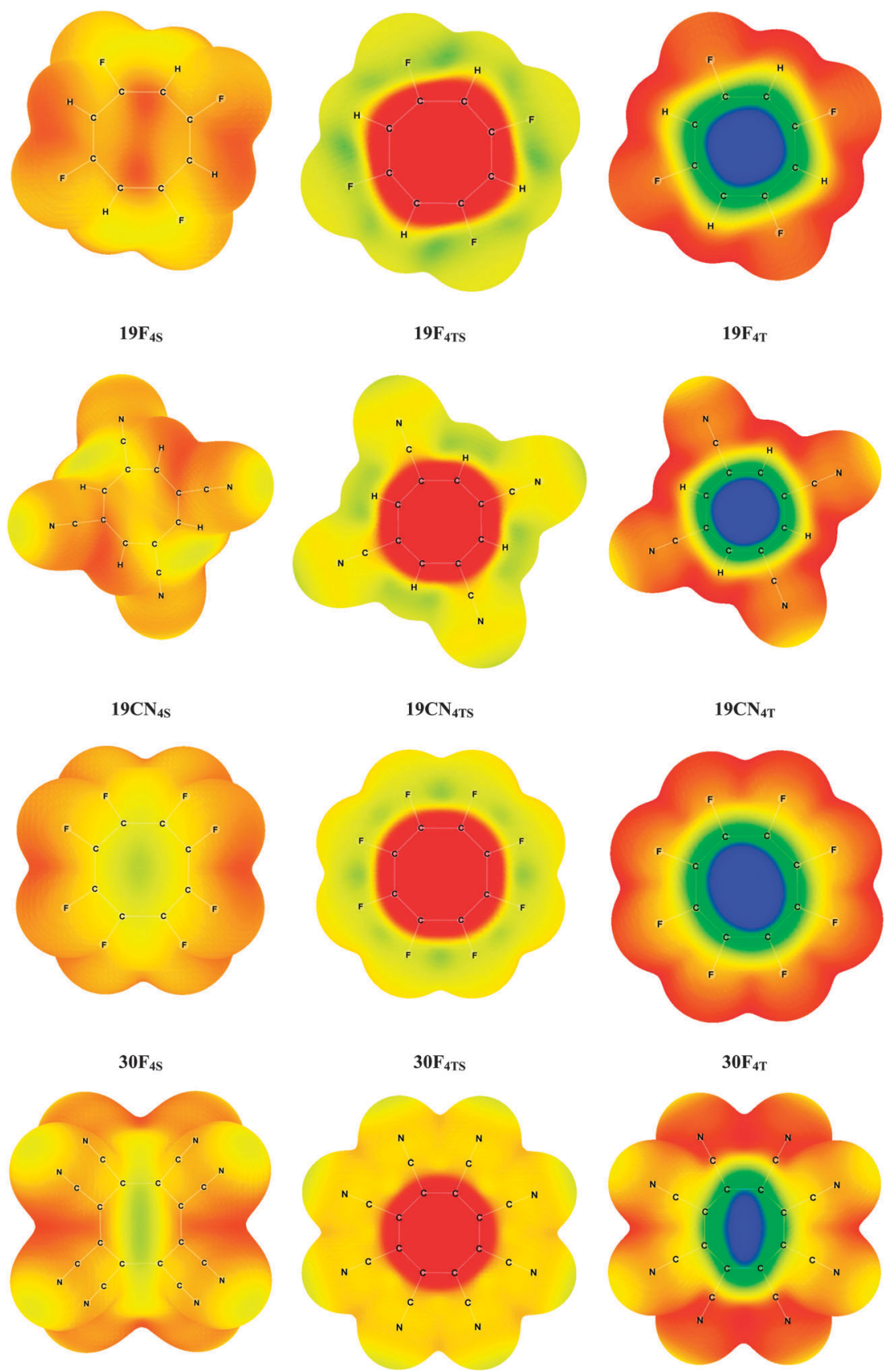

$30 \mathrm{CN}_{4 \mathrm{~S}}$

$30 \mathrm{CN}_{4 \mathrm{TS}}$

$30 \mathrm{CN}_{4 \mathrm{~T}}$

Fig. 7 3D representation of the NICS values (ppm) on the 0.001 a.u. electron density isosurface of some representative compounds. NICS color scheme: blue $<-4.0,-4.0<$ green $<-2.0,-2.0<$ yellow $<-1.0,-1.0<$ orange $<0.0$, red $>0.0$. 
values) in $\mathbf{1 C O T}_{\mathbf{S}}$, to orange in $\mathbf{1 9 X}_{\mathbf{4 S}}$ and finally to light green (negative NICS values) in the octa-substituted systems. However, all those compounds are still considered as non-aromatic. Transition states present similar aromatic changes, with an increase in their aromaticity upon substitution. Those changes are visible on the red area over the ring which shrinks with the substitutions. Finally, in fluoro derivatives' triplet states, despite a reduction of the negative (blue) area located in the centre of the rings being observed, upon substitution, the NICS values show an increase of the aromaticity from the parent $\mathbf{1 C O T}_{\mathbf{T}}$ to $\mathbf{3 0 X}_{\mathbf{8 T}}$. In the case of triplet states of cyano derivatives, the blue area above the ring centre suffers a pronounced reduction indicating a drastic loss of aromatic character. This is also supported both by NICS values and HOMA indexes.

In general, singlet and transition states are non aromatic. When an electron withdrawing atom substitutes an $\mathrm{H}$ atom an increase of the electron delocalization, i.e. a reduction of the number of effective electrons on the ring results, and thus, a loss of the antiaromaticity should be observed, as showed in Table 4.

However, the effect of the substitution on triplet state systems leads to a different picture. On the one hand, fluoro derivatives show a decrease on the NICS values upon substitution. One should expect that the withdrawing effect of fluorine atoms will deplete the ring electron density leading to less aromatic systems. However, the opposite is found in our results in agreement with the previous findings of Kaipio ${ }^{71}$ and later on Torres-Vega ${ }^{72}$ in benzene derivatives. Fluorine atoms are good $\sigma$-acceptor and at the same time good $\pi$-donors due to their lone pairs. Due to its electronegativity, F atoms withdraw electron density from $\sigma$ bonds, and simultaneously, retrodonate electron density into the $\mathrm{C}$ atoms. As stated by Kaipio et al. ${ }^{71}$ "in fluorinated benzene, carbons are somewhat electron depleted as compared to benzene". Same depletion has been found in fluorinated COT (Fig. 8) in which the C atoms that are substituted present a drastic loss of charge. Since NICS values depend mainly on the $\pi$-electron density currents above and below the ring and have less contributions from the centre of the ring, this may cause the NICS values to provide an unrealistic view in this special case.

On the other hand, as observed for triplet state cyano derivatives, Fig. 8, the carbon rings do not suffer such a depletion provoked by the substituents. As a consequence, the aromatic behavior of the cyano derivatives described by NICS values is coherent with the substitution of $\mathrm{H}$ atoms by $\mathrm{CN}$ groups, decreasing the aromaticity (higher NICS values) with the number of substitutions (Table 4).

Finally, to provide more information on the effect of atomic substitution on the aromaticity from a structural point of view, HOMA indexes have been calculated (Table 4). HOMA indexes in singlet state flouro and cyano derivatives range from -0.21 to 0.08 and from -0.22 to -0.56 , respectively, indicating a nonaromatic character in both cases. Fluoro derivatives' triplet states show HOMA indexes close to those of COT (revealing aromatic character), but with a slight decrease with the number of F. In the case of triplet state cyano systems, the decrease on the HOMA indexes is more pronounced, from $0.91\left(\mathbf{2 C N}_{\mathbf{1 T}}\right)$ to

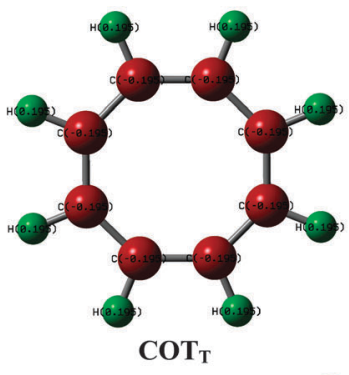

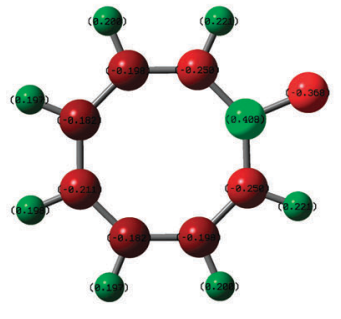

$2 F_{1 T}$

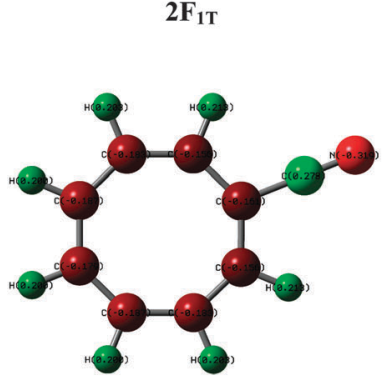

${ }_{2} \mathrm{CN}_{1 \mathrm{~T}}$

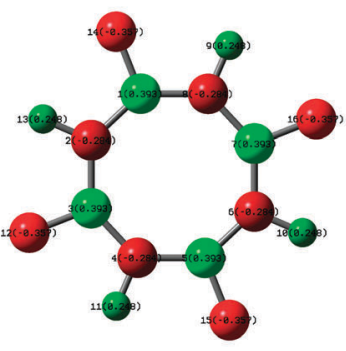

19F $_{4 T}$

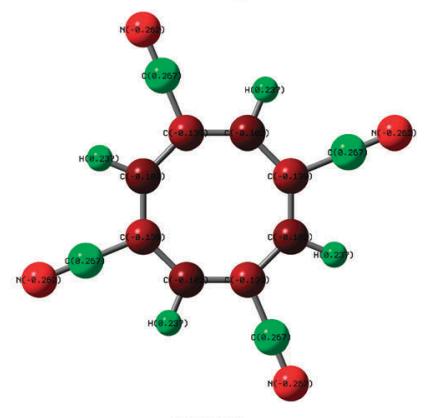

${ }_{19 \mathrm{CN}_{4 T}}$

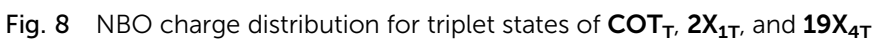
at B3LYP/6-311++G(d,p) computational level. Colour range -0.40 e (red) to 0.40 e (green).

$0.62\left(\mathbf{3 0 C N}_{\mathbf{8 T}}\right)$, describing a loss of aromaticity and confirming our previous findings. Finally, regarding the transition states, both $\mathrm{F}$ and $\mathrm{CN}$ derivatives show non aromatic character in all the cases. The $\mathrm{F}$ derivatives present a narrower range of variation in the HOMA indexes with the substitutions $(-0.22$ to $-0.26)$ than the cyano cases $(-0.21$ to -0.40$)$. Despite the fact that both NICS values and HOMA indexes similarly describe the aromatic character of these compounds, no correlation between those quantities has been found.

\section{Conclusions}

An exhaustive and systematic study of the structural and aromaticity properties of cyclooctatetraene (COT) upon substitution of hydrogen atoms by fluoro and cyano groups have been carried out at B3LYP/6-311++G(d,p) computational level.

As it happened with the unsubstituted compound COT, two different structures have been identified: boat-like or tubshape, which is associated with ground singlet states, and planar structure, which belongs to triplet and transition states. According to the $\mathrm{C}-\mathrm{C}$ distances and Wiberg bond indexes, singlet and transition state structures present alternant single 
and double bonds, while triplet state systems show benzenelike $\mathrm{C}-\mathrm{C}$ bonds. Upon substitution, fluoro derivatives exhibit a decrease of the $\mathrm{C}-\mathrm{C}$ distance up to four substitutions, then a slight increase is observed up to full substitution. However, in all the singlet, triplet and transition states of the cyano derivatives, $\mathrm{C}-\mathrm{C}$ bond distances increase compared to the parent compound, 1COT. It is worth noting, that while in triplet states of fluoro derivatives the planar structure is kept along the whole substitution series, in the cyano systems, compounds $\mathbf{2 5 C N}_{\mathbf{6 T}}$, $\mathbf{2 7}_{\mathbf{C N}}$, and $\mathbf{3 0 C N}_{\mathbf{8 T}}$ have boat-like structure, and $\mathbf{2 0 C N}_{\mathbf{5 T}}$, $\mathbf{2 6 C N}_{\mathbf{6 T}}$, and $\mathbf{2 9 C N}_{\mathbf{7 T}}$ present twisted conformations.

Regarding the relative energies of those compounds with the same number of substitutions, it has been found that the most stable ones were those where the $\mathrm{X}$ groups were more separated. Those compounds with sequential substitutions, i.e. with the $\mathrm{X}$ groups in consecutive order, are those with the largest relative energy. This probably is due to the repulsion between the $\mathrm{X}$ groups which destabilise the structures. Free-Wilson models have been developed to estimate the average energetic effect of the different disposition of the substituents in the systems studied. Inversion barriers $\left(\Delta E_{\mathrm{TS}}\right)$ increase with the number of substitutions, up to twice the COT value in the case of fluoro derivatives, and three times larger in the cyano systems.

Aromatic characteristics of the compounds studied have been analysed in terms of NICS values at 0,1 , and $2 \AA$ over the centre of the ring, NICS profiles, 3D NICS isosurfaces and HOMA indexes. NICS values show an increase of the aromatic character of the ground singlet states, both in fluoro and cyano derivatives. Same observation is found for transition states for both series of substituted systems; however, TS remain antiaromatic even with eight simultaneous substitutions.

In the case of triplet states, fluoro derivatives show an increase in their aromatic behaviour upon substitution, supported by NICS values at 0,1 and $2 \AA$, NICS profiles and NICS values on the 0.001 a.u. electron density isosurfaces. However, due to the electron density depletion on the $\mathrm{C}$ atoms of the ring and the NICS dependence on the electron density on those $\mathrm{C}$ atoms, in this specific case, NICS values do not show the expected loss of aromaticity and they should be considered carefully. On the other hand, triplet states for cyano derivatives show an increase of the NICS values and, therefore, a loss of aromaticity upon substitution. Finally, HOMA indexes corroborate the aromaticity changes described by NICS values, despite the fact that no correlation has been found between both quantities.

\section{Acknowledgements}

We thank the Ministerio de Ciencia e Innovación (Project No. CTQ2012-13129-C02-02) and the Comunidad Autónoma de Madrid (Project FOTOCARBON, ref. S2013/MIT-2841) for continuous support. Thanks are given to the CTI (CSIC) and to Irish Centre for High-End Computing (ICHEC) and for allocation of computing time. G.S.-S. wants to thank to Human Frontier Science Program (Project Reference: LT001022/2013-C) for the support. Ms Aoife Crowe is acknowledged for her careful reading and help.

\section{References}

1 J.-I. Nishida, S. Tsukaguchi and Y. Yamashita, Chem. - Eur. J., 2012, 18, 8964-8970.

2 A. Shimizu and Y. Tobe, Angew. Chem., Int. Ed., 2011, 50, 6906-6910.

3 R. Islas, T. Heine and G. Merino, Acc. Chem. Res., 2012, 45, 215-228.

4 G. Merino, T. Heine and G. Seifert, Chem. - Eur. J., 2004, 10, 4367-4371.

5 O. Bastiansen, O. Hassel and A. Langseth, Nature, 1947, 160, 128.

6 H. S. Kaufman, I. Fankuchen and H. Mark, Nature, 1948, 161, 165.

7 H. Schmidbaur and S. F. Gamper, Organometallics, 1992, 11, 986-989.

8 T. Nishinaga, T. Ohmae and M. Iyoda, Symmetry, 2010, 2, 76-97.

9 R. Breslow, Acc. Chem. Res., 1973, 6, 393-398.

10 T. Nishinaga, T. Ohmae, K. Aita, M. Takase, M. Iyoda, T. Arai and Y. Kunugi, Chem. Commun., 2013, 49, 5354-5356.

11 A. Y. Sokolov, D. B. Magers, J. I. Wu, W. D. Allen, P. v. R. Schleyer and H. F. Schaefer, J. Chem. Theory Comput., 2013, 9, 4436-4443.

12 P. M. Thomas and A. Weber, J. Raman Spectrosc., 1978, 7, 353-357.

13 P. G. Wenthold, D. A. Hrovat, W. T. Borden and W. C. Lineberger, Science, 1996, 272, 1456-1459.

14 G. Deganello, Transition metal complexes of cyclic polyolefins, Academic Press, New York, 1979, ch. 11.

15 J. Dominikowska and M. Palusiak, New J. Chem., 2010, 34, 1855-1861.

16 H. Wang, H. Wang, D. Die and R. B. King, Transition Met. Chem., 2014, 39, 95-109.

17 G. Martinez-Guajardo, Z. Gomez-Saldoval, D. F. Jana, P. Calaminici, C. Corminboeuf and G. Merino, Phys. Chem. Chem. Phys., 2011, 13, 20615-20619.

18 P. B. Karadakov, J. Phys. Chem. A, 2008, 112, 12707-12713.

19 H. O. Henrik, Nat. Chem., 2012, 4, 969-971.

20 G. Sánchez-Sanz, I. Alkorta, C. Trujillo and J. Elguero, Tetrahedron, 2012, 68, 6548-6556.

21 J. I. Wu, I. Fernández, Y. Mo and P. v. R. Schleyer, J. Chem. Theory Comput., 2012, 8, 1280-1287.

22 H. S. Rzepa and N. Sanderson, Mol. Phys., 2005, 103, 401-405.

23 E. Vogel, H.-J. Altenbach and D. Cremer, Angew. Chem., Int. Ed., 1972, 11, 935-937.

24 J. Dominikowska and M. Palusiak, J. Comput. Chem., 2011, 32, 1441-1448.

25 M. Palusiak and T. M. Krygowski, New J. Chem., 2009, 33, 1753-1759.

26 H. Li, H. Feng, W. Sun, Q. Fan, R. B. King and H. F. Schaefer III, New J. Chem., 2014, 38, 6031-6040.

27 G. Schröder, G. Kirsch, J. F. M. Oth, R. Huisgen, W. E. Konz and U. Schegg, Chem. Ber., 1971, 104, 2405-2411.

28 N. E. Takenaka, R. Hamlin, T. Spector, C. P. Junk and D. M. Lemal, Isr. J. Chem., 1999, 39, 141-146. 
29 M. J. Gerace, D. M. Lemal and H. Ertl, J. Am. Chem. Soc., 1975, 97, 5584-5586.

30 D. M. Lemal, J. M. Buzby, A. C. Barefoot, M. W. Grayston and E. D. Laganis, J. Org. Chem., 1980, 45, 3118-3120.

31 C. A. Harmon and A. Streitwieser, J. Org. Chem., 1973, 38, 549-551.

32 L. A. Paquette, W. Kitching, W. E. Heyd and R. H. Meisinger, J. Am. Chem. Soc., 1974, 96, 7371-7372.

33 K. Saito and T. Mukai, Bull. Chem. Soc. Jpn., 1975, 48, 2334-2335.

34 D.-R. Handreck, D. Hunkler and H. Prinzbach, Angew. Chem., 1989, 101, 1386-1388.

35 M. Oda, A. Yamamuro and T. Watabe, Chem. Lett., 1979, 1427-1430.

36 L.-M. Frutos, O. Castaño and M. Merchán, J. Phys. Chem. A, 2003, 107, 5472-5478.

37 B. B. Laird and R. E. Davis, Acta Crystallogr., Sect. B: Struct. Crystallogr. Cryst. Chem., 1982, 38, 678-680.

38 K. H. Claus and C. Kruger, Acta Crystallogr., Sect. C: Cryst. Struct. Commun., 1988, 44, 1632-1634.

39 A. D. Becke, J. Chem. Phys., 1993, 98, 5648-5652.

40 C. T. Lee, W. T. Yang and R. G. Parr, Phys. Rev. B: Condens. Matter Mater. Phys., 1988, 37, 785-789.

41 M. J. Frisch, J. A. Pople and J. S. Binkley, J. Chem. Phys., 1984, 80, 3265-3269.

42 P. v. R. Schleyer, C. Maerker, A. Dransfeld, H. Jiao and N. J. R. v. E. Hommes, J. Am. Chem. Soc., 1996, 118, 6317-6318.

43 F. London, J. Phys. Radium, 1937, 8, 397-409.

44 R. Ditchfield, Mol. Phys., 1974, 27, 789-807.

45 I. Alkorta, G. Sánchez-Sanz, C. Trujillo, J. Elguero and R. M. Claramunt, ARKIVOC, 2012, ii, 85-106.

46 G. Sánchez-Sanz, C. Trujillo, I. Rozas and J. Elguero, Tetrahedron, 2013, 69, 7333-7344.

47 F. Bulat, A. Toro-Labbé, T. Brinck, J. Murray and P. Politzer, J. Mol. Model., 2010, 16, 1679-1691.

48 M. J. Frisch, G. W. Trucks, H. B. Schlegel, G. E. Scuseria, M. A. Robb, J. R. Cheeseman, G. Scalmani, V. Barone, B. Mennucci, G. A. Petersson, H. Nakatsuji, M. Caricato, X. Li, H. P. Hratchian, A. F. Izmaylov, J. Bloino, G. Zheng, J. L. Sonnenberg, M. Hada, M. Ehara, K. Toyota, R. Fukuda, J. Hasegawa, M. Ishida, T. Nakajima, Y. Honda, O. Kitao, H. Nakai, T. Vreven, J. A. Montgomery, Jr., J. E. Peralta, F. Ogliaro, M. Bearpark, J. J. Heyd, E. Brothers, K. N. Kudin, V. N. Staroverov, R. Kobayashi, J. Normand, K. Raghavachari, A. Rendell, J. C. Burant, S. S. Iyengar, J. Tomasi, M. Cossi, N. Rega, N. J. Millam, M. Klene, J. E. Knox, J. B. Cross, V. Bakken, C. Adamo, J. Jaramillo, R. Gomperts, R. E. Stratmann, O. Yazyev, A. J. Austin, R. Cammi, C. Pomelli, J. W. Ochterski, R. L. Martin, K. Morokuma, V. G. Zakrzewski, G. A. Voth, P. Salvador, J. J. Dannenberg, S. Dapprich,
A. D. Daniels, Ö. Farkas, J. B. Foresman, J. V. Ortiz, J. Cioslowski and D. J. Fox, Gaussian 09.D01, Gaussian, Inc., Wallingford CT, 2009.

49 A. E. Reed, L. A. Curtiss and F. Weinhold, Chem. Rev., 1988, 88, 899-926.

50 E. D. Glendening and F. Weinhold, J. Comput. Chem., 1998, 19, 593-609.

51 E. D. Glendening, J. K. Badenhoop and F. Weinhold, J. Comput. Chem., 1998, 19, 628-646.

52 J. Kruszewski and T. M. Krygowski, Tetrahedron Lett., 1972, 13, 3839-3842.

53 N. Szwacki, V. Weber and C. Tymczak, Nanoscale Res. Lett., 2009, 4, 1085-1089.

54 I. Alkorta, J. Elguero, I. Rozas and A. T. Balaban, THEOCHEM, 1990, 206, 67-75.

55 I. Alkorta, J. Elguero, I. Rozas and A. T. Balaban, THEOCHEM, 1990, 208, 63-77.

56 I. Alkorta, J. Elguero, I. Rozas and A. T. Balaban, THEOCHEM, 1991, 228, 47-60.

57 H. Kubinyi and O. H. Kehrhahn, J. Med. Chem., 1976, 19, 1040-1049.

58 I. Alkorta, F. Blanco and J. Elguero, Tetrahedron, 2008, 64, 3826-3836.

59 A. Stanger, J. Org. Chem., 2006, 71, 883-893.

60 R. Ghiasi, THEOCHEM, 2008, 853, 77-81.

61 M. Z. Kassaee, M. Ghambarian and S. M. Musavi, Heteroat. Chem., 2008, 19, 377-388.

62 C. A. Tsipis, Coord. Chem. Rev., 2005, 249, 2740-2762.

63 M. Winkler, B. Cakir and W. Sander, J. Am. Chem. Soc., 2004, 126, 6135-6149.

64 I. Alkorta, L. Azofra, G. Sánchez-Sanz and J. Elguero, Struct. Chem., 2012, 23, 1245-1252.

65 M. Solà, F. Feixas, J. O. C. Jiménez-Halla, E. Matito and J. Poater, Symmetry, 2010, 2, 1156-1179.

66 P. von Ragué Schleyer, M. Manoharan, Z.-X. Wang, B. Kiran, H. Jiao, R. Puchta and N. J. R. van Eikema Hommes, Org. Lett., 2001, 3, 2465-2468.

67 M. Baranac-Stojanović, A. Koch and E. Kleinpeter, Chem. Eur. J., 2012, 18, 370-376.

68 J. J. Torres, R. Islas, E. Osorio, J. G. Harrison, W. Tiznado and G. Merino, J. Phys. Chem. A, 2013, 117, 5529-5533.

69 R. Islas, G. Martínez-Guajardo, J. O. C. Jiménez-Halla, M. Solà and G. Merino, J. Chem. Theory Comput., 2010, 6, 1131-1135.

70 G. Sánchez-Sanz, Tetrahedron, 2015, 71, 826-839.

71 M. Kaipio, M. Patzschke, H. Fliegl, F. Pichierri and D. Sundholm, J. Phys. Chem. A, 2012, 116, 10257-10268.

72 J. J. Torres-Vega, A. Vásquez-Espinal, L. Ruiz, M. A. FernándezHerrera, L. Alvarez-Thon, G. Merino and W. Tiznado, ChemistryOpen, 2015, DOI: 10.1002/open.201402110. 